\title{
Value Analysis of Sports Industry Policy from the Perspective of Na- tional Governance
}

Zhixiong Huang*

Fujian Chuanzheng Communications College, Fujian 350007, China. E-mail:645651928@qq.com

\begin{abstract}
Nowadays, along with the concern of health of people, policy of our country's sports industry is also in constant innovation and improvement. In order to better promote the development of China's sports industry, since the founding of the People's Republic of China, the government has adjusted policies related to the sports industry, and made innovations and improvements. Standing on the perspective of governance, the government puts forward the more perfect policy system of sports industry. Countries should stand in the angle of the diversity on the perfection of sports industry policy, building the coordinated development of industry structure. This paper will focus on the value of sports industry policy from the perspective of national governance and analyze the relevant content.
\end{abstract}

Keywords: National Governance; Sports Industry; Policy; Value

\section{Introduction}

In the relevant reports of our party, it is proposed that the governance system and governance capacity are the core forces to ensure the development of socialism with Chinese characteristics. For the sports industry, the government also wants to establish and perfect the corresponding policies, implement the reform and optimization of sports industry, so as to better play the role of the government's macro regulation and control for the industry. Only by finding out the problems existing in the sports industry, optimizing and dealing with these problems in time, can we promote the rapid development of the sports industry. At present, the management of China's sports industry is still in the stage of continuous strengthening, which requires more attention to be paid to the sports industry policy, so as to better play the value of the sports industry policy.

\section{The historical process of the relevant policy reform in China's sports industry}

\subsection{From the founding of People's Republic of China to the stage of reform and opening up}

At this stage, the development of sports industry in our country is still at the primary stage. Under the background of planned economy, the government has also begun to attach great importance to the sports industry. This move has become the focus of the development of the sports industry. In the government's management thinking, the management process needs to follow the plan. But this will also cause some impact, that is, the management and regulation of sports-related resources do not meet the needs of the public. This also shows that it is far from enough to improve the current situation of China's sports industry only by improving and perfecting relevant laws and regulations. For example, the Soviet Union once paid too much attention to the development of heavy industry while ignoring the develop-

Copyright (C) 2021 Zhixiong Huang

doi: $10.18686 / \mathrm{mmf} . v 5$ i1.2970

This is an open-access article distributed under the terms of the Creative Commons Attribution Non-Commercial License

(http://creativecommons.org/licenses/by-nc/4.0/), which permits unrestricted non-commercial use, distribution, and reproduction in any medium, provided the original work is properly cited. 
ment of the tertiary industry, which also led to the desolation of the tertiary industry in the Soviet Union. At this time, people pay more attention to the political value of the sports industry, but ignore the attributes and economic functions of the sports industry, which also brings a certain impact on the development of the sports industry.

\subsection{From reform and opening up to southbound talks}

With the development of reform and opening up, every aspect of China's market system has been reformed. Correspondingly, sports industry policies are being optimized. In the process of optimization, attention must be paid to the economic benefits of sports industry, and attention should be paid to the input and use of equipment production. In 1986, the sports system reform had a preliminary model, which made China's political cause and sports industry gradually get a better transition, but also better promote the rapid development of the sports industry ${ }^{[1]}$. In this stage, the key point of sports policy reform is to transform the relevant units into profit-oriented ones, and to broaden the types and services of operation. In addition, it is necessary to continuously attract funds and establish corresponding competition activities.

\subsection{The stage of southbound conversation to 2013}

After the southbound talk, China's market economy mechanism has undergone corresponding changes and improvements, and the goal of China's market economy has been better defined. Gradually, China's sports industry related policies and economic levels are becoming more clear. The introduction of more and more policies has greatly promoted the development of the sports industry. With China's accession to the WTO, in the process of achieving globalization of the economy, this action has better promoted the development of sports industry policies in the direction of globalization. China has concentrated on the introduction of some policies to promote the innovation of sports industry, so as to better carry on the economic value of sports industry and promote social harmony and stability.

\subsection{From 2013 to now}

In 2014, China issued relevant policies, which better realized the goal of the sports industry rising to the national level, and the state gave better encouragement and support. More and more sports institutions went to the market, giving full play to the economic value of sports, and sticking to the road of socialist development. China's sports industry policies are constantly optimized and innovated, which requires the coordinated development of multiple departments. From the thought of control to the thought of governance, with the intervention of multiple subjects, the influence of policy has been better played. Governance is both pluralistic and increasingly decentralized.

\section{Basic value analysis of sports industry policy from the perspective of na- tional governance}

\subsection{Value of guidance}

One of the most important features of the sports industry is that the government can intervene in it accordingly, which can better support the development of relevant industries and promote the progress of the industry. In 2012 , a guideline was issued to actively establish the position of the sports industry and give full play to its role in economic development. And the policy has also formulated the corresponding policy support. From the perspective of domestic macro-economic control, the rapid development of sports industry not only can realize the spread of social culture, build a harmonious and stable social environment, but also can improve people's physical quality, and promote the development of national economy. Looking into the future development of the sports industry, there are very positive aspects, so the government should provide more support and help for the development of the sports industry, and give full play to the guiding role.

\subsection{The value of integration}

Government represents one side of the social and public interests. In the specific operation process of government policy, Completely different internal environmental factors need to be taken into account. One of the important reasons to integrate sports industry policy is that it can realize the rapid and sustainable development of sports industry. Only 
when the sports industry and other industries integrate with each other can the value of each other's industries be better played to promote the development of social economy. As far as the current situation is concerned, there is still a lack of corresponding ideas and opinions, and policy support and guidance are also insufficient, which also leads to the insufficient integration of the sports industry and other industries.

Therefore, in view of the above problems, the following solutions are proposed: First, we should make full use of the experience of some developed countries and earnestly study their advanced ideas; In addition, the government should play a leading role, from the integration of the sports industry to the corresponding policy guidance and support, this cause should be recognized. Then, while the government carries out the corresponding policy optimization of the sports market, it also needs some sports enterprises to strengthen the leadership and give full play to the role of supporting the national policy. From the perspective of policy, only by guiding the coordinated development and integration of sports industry and other industries can the rapid development of sports industry be realized ${ }^{[2]}$.

\subsection{The value of feedback}

With the continuous improvement of people's quality of life in modern times, in the context of diversified development, an important value of sports industry policy is performance feedback. The establishment and consummation of the corresponding mechanism can better realize the industrial integration. The establishment and consummation of the corresponding mechanism can better realize the industrial integration. At the same time, it will attract more individuals and organizations to join. Whether a policy can be promulgated smoothly depends not only on the needs of the policy object, but more importantly, on the requirements of the enterprise group. At the same time, by continuously expanding the scale of participation and providing more ways for individuals and groups to participate, the service-oriented sports industry under the guidance of the government should give full play to its own value, provide more personalized services for the public and meet the needs of the public. In modern times, while people begin to pay more and more attention to physical health, people's demands on the sports industry are also changing. The increase of new functions in the sports industry will enable it to better meet the diverse needs of the public and provide more high-quality sports products for the public.

\subsection{Normative value}

An important value of relevant policy promulgation is reflected in whether it is standardized. It can provide a perfect evaluation standard for people and better regulate the behavior of enterprises. The performance of sports industry policy regulation can help the government to build a more perfect sports market. The development of sports industry will drive the transformation of government functions. That is to say, under the strengthened government's market supervision, the overall planning of the sports industry, and the innovation of the corresponding service mode will create a good market environment. At the same time, the government should also attach importance to the participation of the whole people and take people's health as the national policy development strategy. The sports industry, as an industry with great potential for future development, all the negative factors hindering the development of the sports industry should be paid more attention to and cleaned up in time. In addition, the formation of a complete enterprise policy system will give full play to the functions of the government.

With more and more enterprises joining the sports capital market, the sports industry has achieved rapid development in China. The emergence of this phenomenon also makes us better aware that China's sports enterprises are gradually transforming. Now, people's enthusiasm for entrepreneurship is getting higher and higher. In this context, the entrepreneurial spirit of the people makes the sports industry give full play to its role and value. In addition, the transformation and optimization of the sports market and the corresponding adjustment of the sports management mechanism have made the industry better adapt to the development of China's society and economy ${ }^{[3]}$. Therefore, the government should always adhere to the basic strategy of our country, fully absorb and learn from the successful experience of other countries, and formulate corresponding policies to ensure the vigorous development of the sports industry. We should learn to make use of the social and individual forces to build a good structure of the sports industry. Now people begin to pay more and more attention to environmental protection, so we can integrate the content of green 
sports into the reform of the sports industry. In the end, the government should put its position in a right place. More importantly, it should optimize and innovate the system, reduce the intervention in some trivial matters and correctly understand the functions of the government.

\section{Conclusions}

In short, the sports industry in China has experienced decades of development. The sports management thought is also changing. So countries should fully understand their own positions and roles. Only by focusing on the content of macro-control, perfecting the corresponding system of sports industry and creating effective market, can we give full play to the value of sports industry policy and promote the development and progress of sports industry.

\section{References}

1. Shen Y. Transformation of the value in the development of the sports economy department. Proceedings of the annual conference on sports management 2012. p. $65-66$.

2. Yu K. Reforming the modernization of national governance [Master's thesis]. North point: social sciences academic press 2015; (3) : 112 - 114 .

3. Jiang B. Promoting the modernization of national governance system and governance capacity. Guangming Daily (in Chinese); 2013. p. $11-15$. 